\title{
Précis of memory: a philosophical study
}

\author{
Sven Bernecker
}

Published online: 2 November 2010

(C) The Author(s) 2010. This article is published with open access at Springerlink.com

The book presents a comprehensive and coherent account of the epistemology and metaphysics of memory. It introduces a new taxonomy of memory, defends the contingent dependence of memory on personal identity, argues that memory is logically independent of knowledge and that memory is a generative source of justification, sets forth a new version of the causal theory of memory, develops an externalist account of memory content, and proposes an account of memorial authenticity.

Philosophers typically impose a tripartite division on kinds of memory: practical, propositional, and experiential memory. Practical memory is remembering how to do something. Propositional memory is remembering that $p$, where ' $p$ ' stands for a veridical proposition. Experiential memory is remembering from the first-person perspective an event one has personally experienced. The problem with this taxonomy is that there is no way of drawing a sharp and intuitively compelling distinction between experiential and propositional memory. In lieu of the tripartite classification scheme, Chapter 1 proposes a classification in terms of the grammatical objects of the verb 'to remember'. Given this approach, there are four main kinds of remembering: one can remember persons or things, properties, events, and propositions (facts).

The book concentrates on propositional memory, whereby I mean any substituent of the schema 'S remembers that p', irrespective of whether ' $p$ ' refers to something one has personally experienced, and irrespective of whether the memory content consists merely of $\mathrm{p}$ or whether it also includes images or qualitative experiences. Propositional memory of one's own mental states I call introversive memory. All other kinds of propositional memories are extroversive memories. To cut the topic to a manageable size, the book is mainly concerned with propositional memories that

\footnotetext{
S. Bernecker $(\square)$

Department of Philosophy, University of California, Irvine, CA 92697-4555, USA

e-mail: s.bernecker@uci.edu
} 
are both conscious and explicit and are memory-related to past episodes of propositional awareness.

Chapter 2 discusses the relation between memory and personal identity. Whether a memory presupposes personal identity crucially depends on whether its content involves an indexical reference to the rememberer. When the content refers to the rememberer, the veridicality constraint on memory demands that the rememberer is numerically the same as the one who had the original representation. But when the remembered content doesn't involve an indexical reference to the rememberer its truth value isn't affected by whether personal identity is preserved. In this case it is possible for the bearer of the memory state to be different from the bearer of the original representation.

Of what kind is the dependence of memories with reflexive content on personal identity? If memories entailed personal identity, memory couldn't be used to define personal identity. But the standard view has it that personal identity consists in psychological connectedness and continuity, where memories are an important ingredient of psychological connectedness and continuity. Following Parfit and Shoemaker, I propose to solve this problem by arguing that the dependence of memories on personal identity is of a contingent rather than a logical kind. This thesis is defended against objections from constitutive holism, the causal theory of memory, and the immunity to error through misidentification.

Chapter 3 takes issue with the widely held view that to remember something is to know it, where this knowledge was previously acquired and preserved. It is argued that memory is not knowledge-entailing, for sometimes, though hitting the mark of truth, memory succeeds in an epistemically defective way. Unlike knowledge, memory doesn't entail justification (however construed). It is not necessary for propositional memory that the proposition be justifiably believed when it was originally acquired or that it be justifiably believed when it is recalled. Not only can you remember something you didn't justifiably believe in the past but also you may acquire in the meantime some convincing yet misleading evidence that destroys the epistemic status of the once-genuine justified belief that one still remembers. What passes into memory may be merely a representation or belief, not knowledge. ('Representation', the way I use the term, refers to any kind of cognitive pro-attitude towards a proposition.) Just as memory doesn't entail justification it doesn't entail belief. Not only can you remember that $\mathrm{p}$ without believing that you remember $\mathrm{p}$, but you can remember that $\mathrm{p}$ without believing that which you remember, namely $\mathrm{p}$.

Though memory doesn't entail justification and knowledge, memories can, of course, be justified and can qualify as knowledge. And so the question arises whether memory is merely a preservative source of justification and knowledge or whether it may also function as a generative source. I argue for moderate generativism, that is, the view that, though memory is a generative source of justification, it cannot bring about new elements of justification. The only way for memory to function as a generative source of justification is by removing defeaters and thereby unleashing the justificatory potential that was already present at the time the belief was initially entertained. If the original belief had no justificatory potential because, say, it was gettierized, memory can't turn it into a justified belief. Memory generates justification 
only by lifting justificatory elements that were previously rebutted or undermined by defeating evidence.

Remembering something is different from learning it anew. Any theory of memory must devise a condition that ensures that the memory content is retained rather than relearned. To remember something, one's present representation must be suitably related to the corresponding past representation. The interpretations of the memory connection fall into three categories: the evidential, simple, and causal retention theory. Chapter 4 weighs up these three interpretations and argues for the causal retention theory: to remember that $\mathrm{p}$ one's present representation must stand in an appropriate causal relation to one's past representation that $\mathrm{p}^{*}$, where $\mathrm{p}$ is identical with, or sufficiently similar to, $\mathrm{p}^{*}$. The main advantage of the causal theory over the non-causal competitors is that it does a better job of explaining the truth of commonsensical statements of the form "If $S$ hadn't represented at $t_{1}$ that $p^{*}$, he wouldn't represented at $\mathrm{t}_{2}$ that $\mathrm{p}$ ".

Chapter 5 argues that a distinction needs to be made between the causal dependence of a memory on a past representation and the causal dependence of a memory on that which retains the past representation B the memory trace. The causal dependence of a memory on a trace is best characterized in terms of INUS conditions: the trace must be at least an insufficient but non-redundant factor of an unnecessary but sufficient condition for the state of recall. This characterization allows us to clearly distinguish remembering something upon being prompted from merely repeating back the prompt itself. The causal dependence of a memory on a past representation is best characterized in terms of counterfactuals. This characterization lets us correctly classify abnormal cases in which the past representation matches the seeming memory by triggering some one-off random causal mechanism which happens to produce the right seeming memory. It also makes it possible to rule out cases where a highly suggestible agent has a seeming memory upon being provided with a true prompting.

Chapter 6 proposes an externalist account of memory contents. Content externalism is the thesis that the individuation conditions of mental content depend, in part, on external (or relational) properties of the subject's physical or social environment rather than on internal properties of the subject's mind and brain. The kind of externalism advocated in the book is pastist externalism. Pastist externalism has it that the content of a memory state is fixed, once and for all, by the environment the subject was in at the time he had the original representation. When some content is stored in memory it is inert to all subsequent environmental changes. Pastist externalism is compared and contrasted with the hypothesis of the extended mind.

Pastist externalism in conjunction with other premisses has the consequence that an environmental change can bring about a conceptual shift which, in turn, can rob us of the ability to remember insofar as we lose the ability to entertain anew some of our past thought contents. This conclusion strikes some as implausible, for the ability to remember is often taken to depend in the first instance on one's mental condition B on factors inside the head B rather than on the physical and social environment one lives in. Chapter 7 explains and defends the context-dependency of memory that follows from content externalism. Doubts concerning the externalist 
thesis that environmental changes can bring about memory failure don't have to be taken seriously, because there are no arguments to substantiate them. The externalist thesis corresponds with psychological data and is compatible with the psychological criterion of personal identity.

While everyone agrees that memory entails truth opinions differ on how to interpret the veridicality constrain on memory. Some hold that a memory must accurately represent objective reality while others hold that it must only accurately reflect one's initial perception of reality. I argue that memory demands both truth and authenticity. Just as the authentic reproduction of a false proposition doesn't qualify as memory, neither does the inauthentic reproduction of a true proposition. Yet in the case of propositional memories of one's past non-factive attitude the content must be only authentic, not veridical.

What does it mean for a memory content to be an authentic reproduction of a past representation? The standard conception in philosophy has it that diachronic content tokens must be of the same type to be memory-related. But this conception is mistaken. Memory is not only a passive device for reproducing contents but also an active device for processing stored contents. As a result of such information processing, the content of a memory state may differ, to some degree, from the content of the original representation. And this raises the question to what extent diachronic content tokens may differ from one another while still being memoryrelated. Chapter 8, argues that a present propositional attitude token is memoryrelated to a past propositional attitude token only if the content of the present token is relevantly entailed by the content of the past token. Since the entailment relation preserves truth, analyzing memorial authenticity in terms of relevant entailment is perfectly compatible with the idea that memory entails truth. It is a consequence of the proposed account of memorial authenticity that the content of a memory state may be entertained for the first time at the time of recall. This view bears some resemblance to the platonic thesis whereby all learning is nothing but remembering.

Propositional memories of one's own mental states make available two kinds of information: information about the proposition and information about the attitude one took towards the proposition. Just as content of a memory state need not be type-identical with the corresponding past content it is not necessary that the psychological attitude one represents on self having taken towards $\mathrm{p}$ is the very same as the attitude one did take towards $\mathrm{p}$. The attitudes need to be only sufficiently similar. But what is the permissible range of aberration between the attitude identified in a memory report and the original attitude? Chapter 8 argues that diachronic attitude tokens are sufficiently similar to stand in a memory-relation to one another if they share the direction of fit and polarity as positive or negative.

The ninth and final chapter, summarizes the arguments of the book, sets forth the definitive analysis of propositional memory, and says a few words about the wider relevance of the study.

Open Access This article is distributed under the terms of the Creative Commons Attribution Noncommercial License which permits any noncommercial use, distribution, and reproduction in any medium, provided the original author(s) and source are credited. 